\title{
Compare Leadership Characteristics of CEOs in Chinese Hospitality Industry: A Case Study of Zhang Yong and Sun Jian
}

\author{
Shuman Wang ${ }^{1} \&$ Yao Ma ${ }^{1}$ \\ ${ }^{1}$ School of Land and Tourism, Luoyang Normal University, Luoyang, China \\ Correspondence: Yao Ma, School of of Land and Tourism, Luoyang Normal University, Luoyang, China. E-mail: \\ mayaofeier@163.com
}

Received: Septemner17, 2020

Accepted: Octomber 4, 2020 Online Published: Octomber 30, 2020

doi:10.5430/bmr.v9n4p1

URL: https://doi.org/10.5430/bmr.v9n4p1

\begin{abstract}
In recent years, the influence of the leadership style and characteristics under the local cultural background on employees' attitudes and behaviors has attracted the attention of scholars at home and abroad. With rapid development, China's catering and hotel industry has produced a number of well-known and influential leaders, such as Zhang Yong and Sun Jian. In this study, Zhang and Sun are selected as the research objects to explore the unique leadership styles and characteristics of entrepreneurs who grew up under the local cultural background. Based on grounded theory, this qualitative study compares and analyzes the characteristics of the two leaders. It conclude that Zhang has a paternalistic leadership style and Sun has a transformational leadership style with Chinese characteristics.
\end{abstract}

Keywords: leadership style, leadership characteristics, China

\section{Introduction}

With the development of economic globalization, the competition between enterprises is becoming more and more fierce. The nature of the business environment we are now confronting calls for a different set of management qualities, of which entrepreneurship, leadership, adaptability, risk-taking and creativity (thinking out of the box) must be the vital components (Naipaul \& Wang, 2009). Leadership is typically understood as taking place in a situation where leaders and followers share a formal group membership (Hogg \& Rast, n.d.).The success or failure of enterprises depends not only on the market, technology and system, but also on the person in charge of the enterprise, namely the supreme leader. It is believed that leaders' personal and physical features have an important effect on followers (Akif, Mazlum, \& Serhat, 2011). Organizational leaders show wide variations in the styles and behaviors which they exhibit at work (Oshagbemi \& Ocholi, 2006). The theatre of present-day management contains elements of both manage and manage and different managers and cultures may use different accents (Hofstede, 1993). As a process of social influence, the concept and structure of leadership may vary from culture to culture.

Global hospitality organizations, in particular, are profoundly affected by a leader's behaviors and personal characteristics and especially the manner in which the leader relates to and influences followers (Brownell, 2010). In China, with the development of globalization and high technology, leaders in hospitality industry are facing new challenges and pressures. Leaders who carry good leadership characteristics will benefit the organization and become an icon within the team (Arif Kamisan \& King, 2013). Influence of localization, leaders of Chinese enterprises also show typical styles and characteristics. Research on leadership characteristics and leadership style of Chinese hospitality industry is of great significance for improving leadership level, service quality and customer satisfaction in the service industry.

Hidilao hot pot is a well-known restaurant enterprise in China. The brand was founded in 1994. Since its establishment, Hidilao has rapidly occupied the market with the "abnormal service concept" and won high praise from customers. From 2008 to 2012, it won the title of "top 100 Chinese catering enterprises" for 5 consecutive years. After more than 20 years of development, Haidilao international holdings co., ltd. has grown into an internationally renowned catering enterprise. By the end of 2017, Haidilao has operated more than 300 direct stores in more than 100 cities including mainland China, Hong Kong and Taiwan, as well as Singapore, the United States, Australia, South Korea, Japan and other countries, with more than 50,000 employees. In September 2018, Haidilao went public. 
Home inns hotel group was founded in 2002. It is the largest chain hotel network system in China and get public on NASDAQ in October 2006. Home inns hotel group continues to innovate the "home" culture and becomes the most influential brand in China's independent innovation economy hotel chain. It has been awarded "China's best economic hotel chain brand" for many years. In Chinese accommodation market, the general average occupancy rate is 50-60\%. However, the occupancy rate of Home inns reaches more than $90 \%$, which is known as the "Myth of Home Inns". In March 2015, Home inns delisting from NASDAQ and became the holding subsidiary of BTS hotels.

Organizations affect the larger society in which they operate, reflecting the norms and values of the people who work within them (Brownell, 2010). It is valuable to explore organization leadership and employee attitudes by studying business cases. In this study, leaders of Hidilao and Home Inns are selected as cases. The purpose of this study is analyzing and comparing how their leadership characteristics influence employees' work attitude and behavior and exploring their unique leadership styles in the context of Chinese local culture. This research reviews the research about the definition of leadership, the kinds of leadership style and the characteristics of good leaders. Then, the study use case study to explore leadership characteristics of CEOs in Chinese Hospitality Industry based on secondary date through qualitative research. At last, this research compares the leadership characteristics and explore the unique leadership styles under Chinese culture background.

\section{Literature Review}

The research on leadership can be traced back to the 1940s. Many scholars give leadership different definition. Brian (2014) defined that leadership is the ability to get followers. General Patton once exclaimed that Leadership is the ability to articulate a vision or a desired path of progress and to motivate others to strive for that vision. Kouzes and Posner (2012) pointed out that leadership is the ability of leaders to motivate others to make outstanding achievements voluntarily in the organization. Leadership has been defined in terms of individual traits, leader behavior, interaction patterns, role relationships, follower perceptions, influence over followers, influence on task goals, and influence on organization culture (Yukl, 2016). Paul Hesse, a world-renowned leader, summed up the concept of leadership in simple words "leadership is influence". In China, leadership is a new concept introduced with the tide of knowledge economy and the revolution of knowledge management. According to scholar's opinion, the definition of leadership can be summarized as a kind of ability that can be cultivated to effectively influence employees' behaviors and motivate employees to realize the common vision of enterprises.

Burns (1978) defined transformational leadership as that leader influence subordinate under in a high level of ideas and moral values, improve subordinate work motivation, enable it to devote themselves to their work, have opportunity to be a leader. Therefore, transformational leadership can be seen as a process that leaders and employees grow up together and motivation level constantly improved. Subsequently, Bass (1985) expanded Burns' transformational leadership theory. Recognizing the meaning of their work will motivate employees to work harder, which is what transformational leadership is all about (Bass, 1985). Transformational leaders exhibit four dimensions: idealized influence (charisma), individualized consideration, intellectual stimulation, and inspirational motivation (Bass \& Avolio, 1990). Scholars generally agree with Bass's four-dimensional structure of transformational leadership. Chaoping and Kan (2008) explored the dimensions of transformational leadership in the context of Chinese culture and showed that four dimensions of transformation leadership are moral modeling, charisma, articulate vision, and individualized consideration. The connotation of individualized consideration in research Chaoping and Kan (2008) is more extensive than Bass' individualized consideration. Individualized consideration focuses not only on work and individual development, but also on employees' family and life (Chaoping \& Kan, 2008). Moral modeling is the unique dimension of transformational leadership in China. In an ordinary organization, managers should set themselves up as role models for employees, and exert an implicit influence on them, in order to achieve organization's goal and vision (Chaoping \& Kan, 2008).

Research on paternalistic leadership began in the 1960s. Dr. Silin first proposed the concept of "paternalistic leadership" by observing and analyzing the leadership behaviors of a large enterprise in Taiwan for one year. Based on Silin's research, Redding expanded the survey area to Chinese enterprises in Hong Kong, Taiwan, the Philippines and southeast Asia, and regarded the unique economic culture of Chinese people as Chinese capitalism. At the same time, the concept of benevolence leadership was put forward and shown in a way of mercy. In the 1980s, Zheng Boxun in Taiwan began to study paternalistic leadership. Farh and Cheng (2000) defined paternalistic leadership as: in the environment of human governance, leaders advocate strict discipline and authority, fatherly kindness and moral integrity of leadership. Farh and Cheng (2000) identified three constituent elements of paternalistic leadership (PL): authoritarianism, benevolence and moral leadership. 
There are many lists of characteristics of good leaders. A list complied at Santa Clara University and the Tom Peters Group included the following traits: (1) honest, (2) competent, (3) forward-looking, (4) inspiring, (5) intelligent, (6) fair-minded, (7) broad-minded, (8) courageous, (9) straightforward, and (10) imaginative (Denehy, 2008). Some scholars focus on the hospitality industry and study how leaders motivate subordinates to provide customers with satisfactory services through their leadership styles. What leadership characteristics should a good leader need in the hospitality industry? Konstantin (2012) conducted on 209 respondents in the field of tourism and hospitality and found important characteristics and skills: energy, mobility, self-confidence, originality and creativity, communication skills and ability to set and track goals. Cheung, King, and Wong (2018) studied 29 middle-level managers in china. They found that the common leadership characteristics among middle-level managers are innovation and entrepreneurship. The identified leadership characteristics coincided with the four dimensions of transformational leadership style (Cheung et al., 2018). In China, scholars' researches on hospitality industry leadership mainly focus on cultivation, development and the relationship between leaderships style and employee's satisfaction. For example, "Impacts of Leadership Style on Employee Job Satisfaction in High Star-rated Hotels: A Case Study of Guangzhou"(Cai \& Long, 2012), "A Follower-centered Perspective on Business Leadership Development (Luo \& Li, 2016))". There is a lack of research on leadership characteristics and styles, so it is valuable to study the leadership characteristics and styles of the hospitality industry.

\section{Research Method}

Qualitative research aims to explore how and why and focus on understanding the process of what's going on in a setting, how those gains were made, and how people there influenced them (Heigham \& Croker, 2009). Grounded theory offers a research method to develop an understanding of social phenomena that is not pre-formed or pre-theoretically developed with existing theory and paradigms (Engward, 2013). Since the objectives of this study are explore how CEOs leadership characteristics influence employees' work attitude and behavior and their unique leadership styles in the context of Chinese local culture, qualitative research method based on grounded theory is a suitable research method for this study to explore how.

Data collection is often the most time-consuming and expensive aspect of primary research. Analysis of existing data can answer important research questions, while often being completed in much less time. Secondary data analysis typically requires less time and monetary resources to conduct as data sets are often obtained at minimal or no cost, data are readily available and therefore take less research staff time, and there is no need to provide incentives to study participants (Dunn, Arslanian-Engoren, DeKoekkoek, Jadack, \& Scott, 2015). The research targets are CEOs who are not convenient to be touched and interviewed by authors. Meanwhile, there are rich materials in the from books, newspapers, magazines and videos. Considering accessibility, this study uses secondary data sources. In order to improve the validity of the study, sample information was collected from multiple sources. Specifically, the data of this study are mainly obtained from the following four aspects: (1) published books; (2) interviews with enterprise managers by media (3) the newspaper; (4) magazine. In the data collection process of this study, the same or similar information expressed in the same source was excluded. Consider to the accurate and credible of report, triangulation is used to examines each information source and finds evidence to support(Creswell, 2019). The content with the most detailed expression and the most information was retained. However, the same or similar information expressed in different sources is retained to ensure the objectivity and accuracy of the information. The study uses content analysis and follows open coding, axial coding and selective coding stages to code original data and analysis leadership characteristics. Since the forms of data source of this research are text and audio, NVivo software are used to aid data analysis.

\section{Findings and Discussion}

\subsection{Leaders' Background}

Compared with the backgrounds of Zhang Yong and Sun Jian, there are both similarities and differences (Table 1). Both are CEOs, but Zhang is also the founder. He regards Haidilao as his own child and has deep feelings with it. He personally participates in the management and gradually develops Haidilao into a listed company. He is very familiar with the management status and organizational culture of the enterprise, which helped him exert his leadership. Neither of them has received the formal education about hotel or catering management. Sun Jian's marketing courses in Australia helped him develop in the hotel industry. Since leaving Sichuan Tractor Factory, Zhang has been focusing on operating Haidilao and has no experience in other industries. Working experience in different industries and multinational companies has enriched Sun's adaptability. As a professional manager, he can quickly integrate into Home inns corporation and start his management. With their leadership and management skills, two leaders have been recognized and honored by the society in their respective industries. 
Table 1. Leader's background

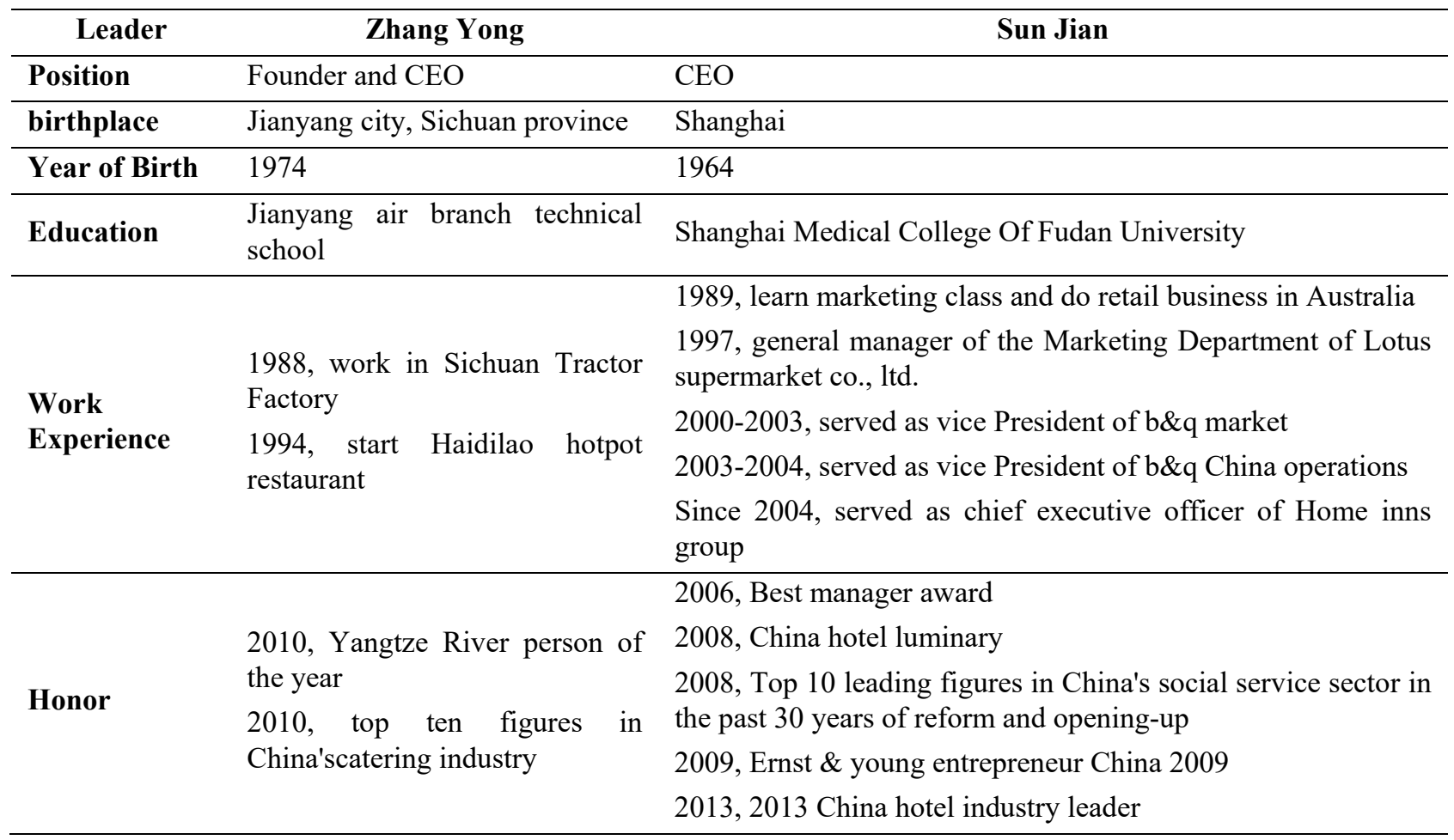

\subsection{Zhang Yong's Characteristics}

\subsubsection{Keep in Faith}

Most of Haidilao's employees come from the countryside and have no education or background. In order to motivate employees, Zhang takes "hands change destiny" as the core value of the enterprise. It lays out a vision for employees: they can create a wonderful life through hard work. Zhang's characteristic of keeping in faith prompted him to establish systems to ensure the implementation of core values, such as clear career development plan and fair promotion system. Haidilao divides its employees into junior, intermediate or senior level. Employees can clearly see their own level and future development direction. This ladder of promotion is visible and tangible, so employees have the motivation to work.

Haidilao's managers are all from internal promotion. New employees, regardless of their education and background, should start at the junior level and be promoted on performance. In the process of internal promotion, the internal staff ability is insufficient and has caused the loss in the work. External talent introduction can inject fresh blood to solve the problem of insufficient capacity of internal staff. However, Zhang insisted on internal promotion even though it was not a very economical decision, because he wanted to give employees enough promotion space to fulfill the promise of changing their fate with both hands. Zhang strictly fulfilled his promise, so that the core values of the staff enterprise were recognized by the staff. The vision he described for the staff won the trust and loyalty of the staff, thus inspiring them to work hard and serve customers wholeheartedly.

\subsubsection{Powerful}

In the early stage of the business, Mr. and Mrs. Zhang Yong, Mr. and Mrs. Shi Yonghong jointly owned Haidilao with equal shares. Mr. Zhang Yong proposed that he wanted to be the manager of restaurant because a store must have one person as the backbone, so as to improve the operation efficiency. In 2004, Zhang “took" $18 \%$ of Mr. and Mrs. Shi's shares in the company at the price of their original investment amount and became the actual controller of Haidilao. Referring to zhang's "bandit robbery", Shi said that "What can I do if I disagree? He (Zhang) always makes the decisions."

In an interview with "China Business News", Zhang said that people who always tell the truth to their bosses will be "killed". He admitted that he craves for greatness and success. It is very nervous to work with Zhang since he loses temper suddenly and never leave human face to employees regardless of the occasion. 
Zhang is a powerful person. This personality trait enables him to take the initiative and play the role of leader in the early stage of the business. At the same time, it also enables him to exert leadership and make others recognize and follow him. Although for followers, they are sometimes unwilling and under pressure. With the principle of maximizing the interests of the organization, they can only obey Zhang Yong's decision. In the early stage of an enterprise, it is really necessary for a person to play a leading role and lead people to achieve the goal. In the context of modest and implicit Chinese culture, Zhang's powerful characteristic make him highlight, take responsibility bravely and improve the execution ability of the organization by means of "order".

\subsubsection{Crisis Awareness}

In an interview with "China Business News", Zhang admitted that he had a high crisis awareness and was always afraid that Haidilao would be crushed or the profits of employees not enough. The high crisis awareness forced him to lead the team to make a difference and strive for innovation.

In order to have an advantage in the market competition and remain attractive to customers, Zhang sets up an innovation performance appraisal system to encourage his employees to continuously innovate services. Employees who are innovative will be rewarded accordingly. In addition to incentives, Zhang also puts pressure on middle-level leaders to encourage employees in their work. Zhang attaches great importance to the innovation of employees and holds monthly special meetings to discuss, study and promote the application. There are blackboard, yellow-board and red-board in Zhang Yong's office, on which are written the names of each manager in restaurant. If the manager has no innovation, his or her name will be written on the blackboard. If the store manager has some suggestions, but no promotion, his or her name will be put on the yellow board. Zhang innovative mechanism has achieved results. For example, the chopsticks for eating hot pot are very long, which was not so long 20 years ago. It was invented by Haidilao.

There is an old saying in China "Learning is like rowing upstream; not to advance is to drop back." Under the influence of the crisis awareness, Zhang knows that if Haidilao do not want to be eliminated by the market, it needed to keep learning. Therefore, he always attached great importance to the employees training and forced them to keep learning. He even establishes Haidilao university. Through training, employees have mastered the skills and abilities that necessary for promotion. It paves the way of them career development which enables employees to realize their own values and goals. While employees achieve personal goals, they also achieve the common goals of the organization.

\subsubsection{Strict}

In an interview with "China Business News", Zhang mentioned that "I am a strict person. Every time I inspect restaurants, I always see a lot of problems." Zhang has very strict requirements on work. It is difficult for his subordinates to be recognized. From the perspective of enterprise development, he strictly implements enterprise standards, regardless of guanxi and human relations. He is strict and firm with employees who violate professional ethics and company regulations. The same is true of those closest to him. With strict characteristic, Zhang urges employees to continuously improve the quality of products and services.

This strict management attitude has formed a fair organizational environment. Although the requirements are very strict, but the employees are very grateful to him. Because of his supervision and encouragement, a large number of employees have changed their fate.

\subsubsection{Helpfulness}

Zhang has the characteristic of helpfulness. His goal is leading employees to get rich together. He creates a big family working environment for employees, where they are called brother and sister, help each other and make progress together. He established a series of humanistic care measures, such as helping employees solve family problems; providing a good living environment for employees; creating a satisfactory working environment for employees; caring about employees' children, paying more attention to employees' leisure cultural life. Under this system, employees' self-esteem is highly valued, and their self-worth is realized. They tend to have a more consistent recognition of the company. Employees regard Haidilao as their home and actively improve their service level, thus creating better performance for the enterprise. These measures help employees solve their worries at home. Therefore, employees can work happily, and happiness arises spontaneously. The smile generated from the heart of employees has become the signature service of Haidilao.

\subsection{Sun Jian's Characteristics}

\subsubsection{Hardworking}

Sun Jian describes himself as a workaholic with obsessive-compulsive disorder. He also likens himself to a "lion + bee" type of person, who is hard-working and capable. Sun basically does not take a vacation. What he eats most when 
working overtime in the office is takeout. Sun sets an example for his employees with his practical actions. At the management conference half a year after taking office, Sun Jian tell the names and hotel positions of all 110 store managers without looking at any materials. Sun wants to convey a message that "Now we are a team". Employees are aware of their role and value in the business and consider themselves as part of the Home inn. In this team, everyone cares about the operation of the enterprise and helps each other instead of just doing their own work. For example, before leaving work, cleaner asks "Is the room full today?". Employees consciously took dozens of promotional materials of Home inn before leaving work and distributed them on their way home.

\subsubsection{Curious}

Sun has always been curious and interested in the world. Just like his experience, he went abroad and returned home, medicine and marketing, retail and hotel. He has always been keen on change and think about what else can do about Home Inn? For an enterprise, it must have some innovations and changes to look for the future opportunities of this team. This curiosity also prompted him to lead the team in continuous innovation. In terms of brand, Home inns group keeps innovating and launches hotels with different themes to meet the needs of different customers, such as Jianguo hotel for high-level business travel and fairyland hotel for leisure and vacation. In 2017, Home inns group launched a new brand, Yihotel, which is equipped with cheongsam and long gown for guests to cross-dress. VR equipment, intelligent projectors and other "new gadgets" have been moved to the hotel.

\subsubsection{Respect}

Sun said that both customers and employees are gods. The softest part of human nature is to be respected. The basis of respect is equality. In Home inn, there is no official position, only different positions, different responsibilities, cleaner and CEO are equal. They are easy to chat with each other. Sun takes the initiative to greet employees and care about their families. The premise of making employees serve customers naturally is that enterprises should serve employees well and pay attention to their living environment. Every time he inspects the hotel, Sun would go to the staff dormitory and restaurant to care about their accommodation.

At the staff meeting of home inn, Sun once choked up and cried on the stage when he talked about the achievements made by front-line employees who made their efforts silently. This kind of affection of Sun Jian is the recognition and respect that pays to employee.

The Home inn focus not only on customers, but also on employees. Through daily practice, it let employees experience the feeling of being respected and served. It passes on the service concept to employees. Gradually, employees develop a habit to bring to their work and let customers accept this signal, forming a virtuous circle.

In 2004, home inns hotel management college was established. Sun personally provides training for employees above the manager level. He said that we should know how to respect our opponents. Don't denigrate them. Learn from others' strengths." Through his words and deeds, Sun has formed a family culture in the enterprise, which is to respect employees, customers and competitors.

\subsubsection{Openness}

When it comes to employees, Sun would say that they are so cute. The employee commented on Sun like this "Sun almost never loses his temper". Sun is a good emotional controller. He always wears a smile on his face, which forms a harmonious atmosphere for enterprises. Employees can freely talk with him about their work. Home inns holds grassroots meeting every year. At this meeting, grassroots employees directly talk to the CEO. They can express their requirements for the future enterprise, their own development, satisfaction and dissatisfaction with the working environment.

Home inn corporation holds an employee's sports meeting every year. Sun also participate in the meeting and compete with employees to create an open, harmonious and warm enterprise environment. Home inns will take its employees to travel every year and let them stay in the hotel, which not only broadens their horizon, but also makes them feel the meaning and value of their work.

\subsection{Comparative Analysis on Leadership Characteristics}

\subsubsection{Powerful vs respect}

Although Zhang is also very concerned about employees and considers their career development. Employees are very grateful and loyal to him. However, he likes to make decisions with his power and demands absolute obedience of employees which make employees feel nervous with him. Sun is very respectful and easy-going to employees. He used his own service-oriented actions to convey the service-concept to employees. In this kind of harmonious and open working environment, employees naturally transfer their inner happiness to customers. 


\subsubsection{Crisis Awareness vs Cautious}

Both leaders in the organization attaches great importance to innovation and ask employees to continuously learn. The reasons for this situation are different, this is a result of the leaders' characteristics. Zhang has a strong sense of crisis and conservative, which causes him a lot of pressure. Under this pressure, Zhang needs to keep innovating without being eliminated. Therefore, he will adopt a combination of hard and soft methods to encourage employees to innovate. Under the internal trend of curiosity and restlessness, Sun Jian tried and created new things to bring innovative experience and personalized service to customers. Sun Jian said he enjoy this process very much.

\subsubsection{Strict vs Openness}

At work, Zhang directly criticize the mistakes of employees, regardless of the occasion and face of employees. Other managers can imitate Zhang's behavior and induces bad influence in the enterprise. At Home inn, Sun Jian always maintains a calm attitude. Employees are free to chat with him about work. The two leaders use different leadership styles to play a role in the organization, one is intense and serious, the other is loose and free.

\subsection{Leadership Style}

By analyzing the characteristics of leaders and their influence in the enterprise, it is found that they have different leadership styles. Through keep in faith, Zhang Yong established a personal image of integrity, responsibility, fairness and selflessness in the organization, so as to win the trust and loyalty of subordinates. It is moral aspect of leadership. In the interaction with subordinates, Zhang never allow employees to challenge their power and authority, require them to obey her without, and exercise strict control over them at work. It is authoritarianism aspect of leadership. Zhang show concern for their subordinates, such as caring for their physical health and family life, helping them deal with problems in life and work, and offering assistance when they are in trouble. It is benevolence leadership. Through analysis, it can be concluded that Zhang leadership style is paternalistic leadership.

Sun Jian works hard and has a strong spirit of dedication. He has a strong innovative spirit, constantly rich hotel brand. In the organization, he has established the unique leadership charism. In the organization, Sun sets an example for employees to serve with a smile and serve from heart, which belongs to charism of moral modeling. Through the experience of stay in Home inns, employees realize the meaning and value of work. Through chatting with employees about work and family, Sun transmit the core value of Home inn to employees. He highly appreciates the efforts of employees and regard them as a team. Sun builds an articulate vision for his employees. Sun cares about the living and working environment of employees, helps them solve their family difficulties, attaches importance to their personal development, trains them, and personally participates in some enterprise activities to get along with employees. It is individualized consideration. Through analysis, it can be concluded that Sun's leadership style contains Chinese culture. It is transformational leadership identified by Chaoping and Kan (2008).

\section{Conclusion}

Through analysis of the characteristics and styles of the two leaders, it is found that both of them show same dimension: moral. The reason can be found in the traditional Chinese culture. China is a highly collectivist country, which attaches great importance to the harmony of interpersonal relations. In addition to the work of employees, managers also care about their lives and families. Confucian culture is deeply rooted in China. It believed that the cultivation of personality and virtue is the cornerstone of society. In the organization, managers should set an example for employees and influence them in a subtle way so that they can make efforts to achieve the goals and missions of the organization. The limitation of this research is only use secondary data source that could not get deeply information about research samples. Future research could adopt multi-research method to examine and expand results.

\section{References}

Akif, T., Mazlum, C., \& Serhat, B. (2011). A Study on the Perception of the Leadership Characteristic by the Employees on the Context of Implicit Leadership Theory. International journal of business and management studies, 3(2).

Arif Kamisan, P., \& King, B. E. M. (2013). Transactional and transformational leadership : a comparative study of the difference between Tony Fernandes (Airasia) and Idris Jala (Malaysia Airlines) leadership styles from 2005-2009. International journal of business and management, 8(24), https://doi.org/10.5539/ijbm.v8n24p107

Bass, B. M. (1985). Leadership and performance beyond expectations. New York: London: New York: Free Press. London: Collier Macmillan.

Bass, B. M., \& Avolio, B. J. (1990). Developing Transformational Leadership: 1992 and Beyond. Journal of European industrial training, 14(5). https://doi.org/10.1108/03090599010135122 
Brian, T. (2014). Leadership (The Brian Tracy Success Library): AMACOM.

Brownell, J. (2010). Leadership in the Service of Hospitality. Cornell hospitality quarterly, 51(3), 363-378. https://doi.org/10.1177/1938965510368651

Burns, J. M. (1978). Leadership (1st ed.). New York: Harper \& Row.

Cai, X., \& Long, M. (2012). Impacts of Leadership Style on Employee Job Satisfaction in High Star-rated Hotels: A Case Study of Guangzhou. Journal of Beijing International Studies University, 7, 29-28.

Chaoping, L. I., \& Kan, S. H. I. (2008). The structure and measurement of transformational leadership in China. Front. Bus. Res. China, 2(4), 571-590. https://doi.org/10.1007/s11782-008-0032-5

Cheung, C., King, B., \& Wong, A. (2018). What does the Industry need to know about Chinese Hospitality Leadership? Journal of China Tourism Research, 14(2), 177-192. https://doi.org/10.1080/19388160.2018.1463882

Creswell, J. W. (2019). Educational research: planning, conducting, and evaluating quantitative and qualitative research (6th ed.). Saddle River, New Jersey: Pearson.

Dunn, S. L., Arslanian-Engoren, C., DeKoekkoek, T., Jadack, R., \& Scott, L. D. (2015). Secondary Data Analysis as an Efficient and Effective Approach to Nursing Research. West $J$ Nurs Res, 37(10), 1295-1307. https://doi.org/10.1177/0193945915570042

Engward, H. (2013). Understanding grounded theory. Nurs Stand, 28(7), 37-41. https://doi.org/10.7748/ns2013.10.28.7.37.e7806

Farh, J. L., \& Cheng, B. S. (2000). A Cultural Analysis of Paternalistic Leadership in Chinese Organizations. https://doi.org/10.1057/9780230511590_5

Heigham, J. D., \& Croker, R. A. D. (2009). Qualitative Research in Applied Linguistics: A Practical Introduction. https://doi.org/10.1057/9780230239517

Hofstede, G. (1993). Cultural constraints in management theories. Academy of Management perspectives, 7(1), 81-94. https://doi.org/10.5465/ame.1993.9409142061

Hogg, M. A. V. K. D., \& Rast, I. D. E. (n.d.). Intergroup leadership in organizations: leading across group and organizational boundaries. Academy of Management Review, 37(2).

Konstantin, P. (2012). Required Skills and Leadership Characteristics of A Modern Manager In Tourism And Hospitality. UTMS journal of economics, 3(1), 91.

Kouzes, J. M., \& Posner, B. Z. (2012). The Leadership Challenge: How to Make Extraordinary Things Happen in Organizations (5th ed.). Somerset: Somerset: Jossey-Bass.

Luo, W., \& Li, P. (2016). A Follower-centered Perspective on Business Leadership. Development. Human Resource Development of China, 4, 26-33.

Naipaul, S., \& Wang, Y. (2009). Entrepreneurship and leadership in hospitality: Insights and implications for hospitality and tourism education - Mr Harris Rosen in conversation with Drs Sandra Naipaul and Youcheng Wang. International Journal of Contemporary Hospitality Management, 21(6), 639-658. https://doi.org/10.1108/09596110910975936

Oshagbemi, T., \& Ocholi, S. A. (2006). Leadership styles and behaviour profiles of managers. Journal of Management Development, 25(8), 748-762. https://doi.org/10.1108/02621710610684231

Yukl, G. (2016). Managerial Leadership: A Review of Theory and Research. Journal of management, 15(2), 251-289. https://doi.org/10.1177/014920638901500207

\section{Copyrights}

Copyright for this article is retained by the author(s), with first publication rights granted to the journal.

This is an open-access article distributed under the terms and conditions of the Creative Commons Attribution license (http://creativecommons.org/licenses/by/4.0/). 